\title{
Prognostic Value of Immunosuppressive Acidic Protein and Oxidative Stress Status in Critically Ill Patients
}

\author{
Elif O Tutuncu ${ }^{1} \odot$, Zerrin D Dundar ${ }^{2} \odot$, Ibrahim Kilinc ${ }^{3} \odot$, Aziz Tutuncu ${ }^{4} \odot$, Sedat Kocak ${ }^{5} \odot$, Abdullah S Girisgin ${ }^{6} \odot$
}

\begin{abstract}
Introduction: The aim of this study was to determine the prognostic value of admission immunosuppressive acidic protein (IAP), interleukin-6 (IL-6), total oxidant status (TOS), and total antioxidant status (TAS) in 161 critically ill patients.

Materials and methods: This prospective observational study was carried out in the Emergency Department ICU for 6 months. Critically ill patients were included in the study consecutively. The main outcomes were the need for early mechanical ventilation (MV) and in-hospital mortality. Results: The mean age of 161 patients was $66.5 \pm 17.1$ years. The median IL-6 levels of patients who required early MV were significantly higher than of the patients who required no MV $(p<0.001)$, and the median IL- 6 levels in the nonsurvivors were significantly higher than in the survivors $(p<0.001)$. The median IAP levels were not significantly different between the groups $(p=0.464$ for early MV and $p=0.340$ for the in-hospital mortality group). The AUCS of IL- 6 and TOS for predicting in-hospital mortality were 0.819 and 0.608 , respectively.

Conclusion: The IAP level on admission to ICU is ineffective in predicting the need for early MV and in-hospital mortality; however, IL-6 level on admission is a strong prognostic predictor in critically ill patients. Our findings showed that the burden of oxidative stress was high in general ICU patients.

Clinical significance: Our study showed that increased oxidative stress is an important problem in critically ill patients. If measures are taken to reduce oxidative stress by physicians, the prognosis of critically ill patients will be better.

Keywords: Immunosuppressive acidic protein, In-hospital mortality, Interleukins, Oxidative stress.

Indian Journal of Critical Care Medicine (2021): 10.5005/jp-journals-10071-23788
\end{abstract}

\section{INTRODUCTION}

Critically ill patients are one of the most important patient groups in modern medicine with advanced medical care requirements and high mortality rates. As a result of immunosuppression and increased total oxidative stress, a clinical process with multiple organ failure appears in most of the critically ill patients with poor prognosis. ${ }^{1-3}$ It is essential to understand these pathophysiological pathways to provide appropriate supportive treatment for critically ill patients.

Immunosuppressive acidic protein (IAP) is an acute-phase reactant in the glycoprotein structure. IAP was firstly defined in the literature as an indicator of tumor size and clinical cancer severity in cancer patients. ${ }^{4}$ It has been reported that IAP is released from T lymphocytes, B lymphocytes, polymorphonuclear leukocytes, and macrophages in cancer patients and that IAP is a valuable marker that can be used as an indicator of survival in solid tumors such as breast, lung, renal, stomach, and colorectal cancer. ${ }^{5-8}$ In different clinical studies conducted after cancer studies, it has been shown that IAP is not only a marker specific to cancer patients but also an acute phase reactant which is determined with the elevated serum levels in inflammatory events, such as rheumatoid arthritis and acute pancreatitis. ${ }^{9,10}$ In the literature, several studies have reported that IAP is released from hepatocytes in acute inflammatory events by stimulation of interleukin-6 (IL-6), and its elevation in serum is correlated with an increase in C-reactive protein and IL- 6 levels. ${ }^{11,12}$

Oxidative stress is defined as the deterioration of the balance between reactive oxygen species and the antioxidant capacity of an organism. Recent studies have shown that the increase in free radical activity is associated with the etiology of many diseases. ${ }^{13-17}$ Total oxidant status (TOS) and total antioxidant status
${ }^{1,4}$ Department of Emergency, Elbistan State Hospital, Kahramanmaras, Turkey

2,5,6 Department of Emergency Medicine, Meram Faculty of Medicine, Necmettin Erbakan University, Konya, Turkey

${ }^{3}$ Department of Biochemistry, Meram Faculty of Medicine, Necmettin Erbakan University, Konya, Turkey

Corresponding Author: Zerrin D Dundar, Department of Emergency Medicine, Meram Faculty of Medicine, Necmettin Erbakan University, Konya, Turkey, Phone: +90 5324682555, e-mail: zerdef@ hotmail.com

How to cite this article: Tutuncu EO, Dundar ZD, Kilinc I, Tutuncu A, Kocak S, Girisgin AS. Prognostic Value of Immunosuppressive Acidic Protein and Oxidative Stress Status in Critically III Patients. Indian J Crit Care Med 2021;25(4):405-410.

Source of support: Nil

Conflict of interest: None

(TAS) measurements reflect the levels of oxidant and antioxidant substances, respectively, in a sample. ${ }^{18,19}$ Oxidative stress index (OSI) is the ratio of total plasma TOS level to TAS level and is an indicator of the net oxidative stress in the body. The evaluation of plasma TAS, TOS, and OSI levels provides key information about the clinical status of critically ill patients. ${ }^{20}$

This prospective study aimed to determine the prognostic values of IAP, IL-6, TOS, and TAS levels, measured on admission in critically ill patients, who were followed up in the emergency intensive care unit (ICU). 


\section{Materials and Methods}

The study protocol was approved by the Drug and Non-Medical Device Research Ethics Committee, Meram Faculty of Medicine, Necmettin Erbakan University, Tukey. Informed consent was obtained from the patients or the first-degree relatives of the patients who were in a coma or had incomplete mental functioning.

\section{Study Population}

This prospective observational study was carried out in the ICU of the emergency department of Meram Faculty of Medicine, Necmettin Erbakan University for 6 months. ICU of Emergency Department serves as one of the Level 3 general ICUs (Level 3 ICUs admit patients requiring two or more organs support and are staffed with nurses with a doctor present in the unit 24 hours daily) in the hospital. Patients requiring critical care, aged 18 years and older who were followed up and treated in the Emergency ICU during the study period were included prospectively in this study. Patients under 18 years of age, pregnant, and those who did not give informed consent to participate were excluded from the study.

\section{Study Protocol}

The following parameters were recorded for patients who met the inclusion criteria: age, gender, APACHE II score, and SOFA score. The patients were followed up for the first three days in terms of the need for mechanical ventilation (MV) and then they were followed up in terms of the length of stay in ICU, length of stay in the hospital, and in-hospital mortality.

The routine blood samples were collected from the patients on admission to the ICU. The blood samples were kept at $-20^{\circ} \mathrm{C}$ until biochemical analysis to measure serum IAP, IL-6, TAS, and TOS levels.

The main prognostic outcomes of the study that were determined included the need for MV in the first three days (early MV) and in-hospital mortality. The patients were divided into two groups: required MV and not required early MV. Differences between clinical parameters and biomarker levels were investigated.

For evaluating the in-hospital mortality, the patients were divided into two groups: survivors and nonsurvivors. Again, the differences between parameters and biomarker levels were also investigated. The prognostic performances of the parameters and biomarkers which were found to be significantly different between the two groups in terms of predicting in-hospital mortality were calculated.

\section{Biochemical Analysis}

IAP and IL- 6 levels of the samples preserved in appropriate conditions were measured with respective ELISA kits (Human IAP ELISA kit, Sunred Biological Technology Co. Ltd., Shanghai, China and Human IL-6 ELISA Kit, Boster Biological Technology, Pleasanton, USA); TOS and TAS levels were measured using Real Assay Diagnostics Total oxidant status (TOS) and total antioxidant status (TAS) kits. The oxidative stress index (OSI) was calculated using the following formula:

OSI $=\left[\right.$ TOS $\left(\mu \mathrm{mol}\right.$ Trolox equiv./L)/TAS $\left(\mu \mathrm{mol} \mathrm{H}_{2} \mathrm{O}_{2}\right.$ equiv./L)] $\times 100$.

The Oxidative Stress Handbook published by the manufacturer of TOS and TAS kits (Real Assay Diagnostics) to guide measurements of TOS and TAS levels and evaluate the results mentions 9 stage clinical status interpretations (best level, very good level, good level, normal level, balance, immunity disorders, oxidative stress, high oxidative stress, and very high oxidative stress) which can be provided with the evaluation of TAS and TOS levels. ${ }^{20}$ It is said that equilibrium occurs at the onset of acute diseases, the TOS value is above 8.00 and the TAS value can be determined above 2.00; however, TAS value below 1.45 indicates very high oxidative stress clinically. ${ }^{20}$

\section{Statistical Analysis}

Statistical analysis of the data was performed using SPSS version 20.0 (SPSS Inc, Chicago, IL, USA). Normality analyses of the data were done by using histograms and the Kolmogorov-Smirnov test. Quantitative variables of normal distribution were expressed as mean \pm standard deviation, quantitative variables that did not conform to normal distribution were expressed as median (25-75 percentiles) and qualitative variables were expressed as frequency (percent).

The difference of the quantitative variables between different groups was evaluated using the Mann-Whitney $U$ test and Independent Samples T-tests. The difference of the qualitative variables between the groups was evaluated by using Chi-square and Fisher's exact tests. A $p$-value of $<0.05$ was considered statistically significant. The in-hospital mortality predictive powers of the biomarkers were evaluated using the receiver-operating characteristic (ROC) analysis. The Area under the ROC curve (AUC) values were determined.

\section{Results}

\section{Demographic Characteristics of the Study Population}

A total of 185 patients were recruited during the 6-month study period. Nine patients were excluded from the study because they were referred to another health care facility shortly after they were taken to the Emergency ICU and five patients were excluded as they left the ICU voluntarily. The blood samples of the remaining 171 patients were collected for biochemical analysis. During the biochemical analysis, since the blood samples of the two patients were not appropriate (grossly hemolyzed), the levels of IAP, IL-6, TAS, and TOS were not measured. Eight patients were excluded from the statistical evaluation as they were referred to another health care facility during the ICU follow-up and clinical outcome information could not be obtained. A total of 161 patients were included in the statistical evaluation (Fig. 1).

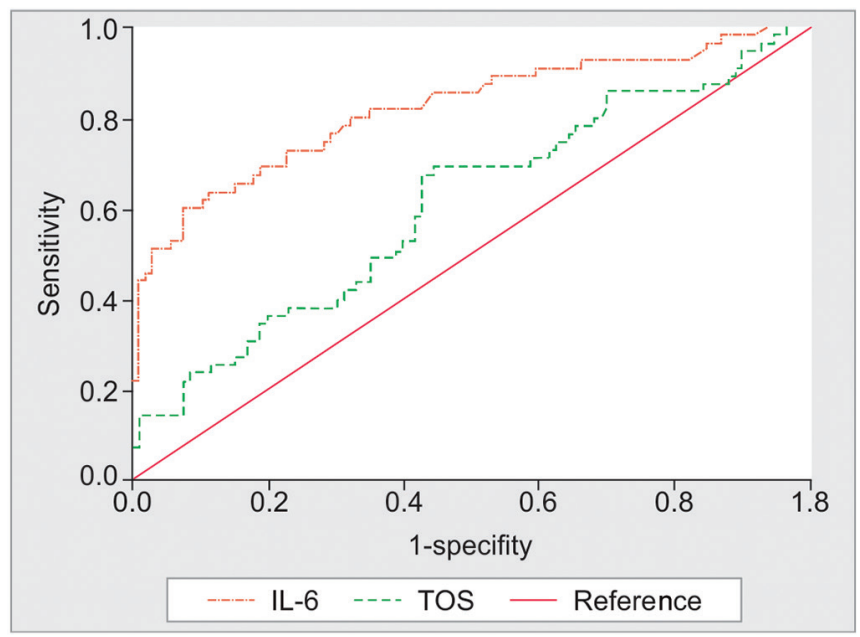

Fig. 1: Study flow chart 
The mean age of finally included 161 patients in this study was $66.5 \pm 17.1$ years and 82 patients $(50.9 \%)$ were males. The leading comorbidities were hypertension (30.4\%), diabetes mellitus (22.4\%), and renal failure (20.5\%). The mean acute physiology and chronic health evaluation II (APACHE II) score of the patients was $23.98 \pm 8.43$ and the mean sequential organ failure assessment (SOFA) score was $6.26 \pm 4.11$. Of 161 patients, 43 (26.7\%) patients required $M V$ within the first three days and the overall in-hospital mortality rate was $34.2 \%$. The demographic characteristics and biomarker levels of all patients included in the current study are shown in Table 1. The oxidative stress status of all patients is shown in Table 2.

Table 1: Characteristics of the study population

\begin{tabular}{lc}
\hline Parameters & $(n=161)$ \\
\hline Age, years & $66.5 \pm 17.1$ \\
Gender, $n$ (\%) & \\
Male & $82(50.9)$ \\
Female & $79(49.1)$ \\
Comorbidity, $n$ (\%) & \\
Hypertension & $49(30.4)$ \\
Diabetes mellitus & $36(22.4)$ \\
Renal failure & $33(20.5)$ \\
Coronary artery disease & $29(18.0)$ \\
Cerebrovascular disease & $27(16.8)$ \\
Respiratory diseases & $21(13.0)$ \\
Malignancy & $19(11.8)$ \\
Heart failure & $18(11.2)$ \\
Others & $36(22.4)$ \\
APACHE II score & $23.98 \pm 8.43$ \\
SOFA score & $6.26 \pm 4.11$ \\
The need for early mechanical & $43(26.7)$ \\
ventilation, $n$ (\%) & \\
The length of stay in ICU, days & $8.15 \pm 11.47$ \\
The length of stay in hospital, days & $11.86 \pm 12.23$ \\
In-hospital mortality, $n$ (\%) & $55(34.2)$ \\
IL-6, pg/mL* & $18.01(4.89-63.86)$ \\
IAP, $\mu$ g/mL* & $315.30(249.80-340.50)$ \\
TAS, mmol Trolox equiv./ $L^{*}$ & $1.19(0.96-1.39)$ \\
TOS, $\mu$ mol $\mathrm{H}_{2} \mathrm{O}_{2}$ equiv./ ${ }^{*}$ & $22.92(14.78-36.76)$ \\
OSI* & $2.06(1.23-3.35)$ \\
\hline
\end{tabular}

*Data presented as median (25-75\%); IL-6, interleukin-6; IAP, immunosuppressive acidic protein; TAS, total antioxidant status; TOS, total oxidant status; OSI, oxidative stress index

\section{Comparison of the Patient Groups Required and Not Required Early Mechanical Ventilation}

There was no significant difference in terms of age and gender between the groups required and not required early MV ( $p=0.356$ and $p=0.269$, respectively). Early MV rates were higher in patients with underlying respiratory diseases $(p<0.001)$. The mean APACHE II and SOFA scores of the patients who required early MV were significantly higher than the patients not required early MV ( $p<0.001$, for both). The in-hospital mortality rate was significantly higher in the patients who required early MV than in the patients not required early MV $(p<0.001)$.

The median IL-6 levels of patients who required early MV were significantly higher than the patients not required early MV $(p<0.001)$, whereas the median IAP levels were not significantly different between the groups ( $p=0.464)$. No statistically significant difference was
Table 2: Oxidative stress status of the patients

\begin{tabular}{|c|c|c|c|c|}
\hline & & \multicolumn{3}{|c|}{ TOS* } \\
\hline \multirow{4}{*}{ TAS $^{* *}$} & $n=161$ & $<5.00$ & $5.00-8.00$ & $>8.00$ \\
\hline & $>2.00$ & $\begin{array}{l}0(0.0 \%) \\
\text { (Best level) }\end{array}$ & $\begin{array}{l}0 \text { (0.0\%) } \\
\text { (Good level) }\end{array}$ & $\begin{array}{l}0(0.0 \%) \\
\text { (Balance) }\end{array}$ \\
\hline & $1.45-2.00$ & $\begin{array}{l}0(0.0 \%) \\
\text { (Very good } \\
\text { level) }\end{array}$ & $\begin{array}{l}1(0.06 \%) \\
\text { (Normal level) }\end{array}$ & $\begin{array}{l}29(18.0 \%) \\
\text { (High oxidative } \\
\text { stress) }\end{array}$ \\
\hline & $<1.45$ & $\begin{array}{l}3(1.9 \%) \\
\text { (Immunity } \\
\text { disorders) }\end{array}$ & $\begin{array}{l}5(3.1 \%) \\
\text { (Oxidative stress) }\end{array}$ & $\begin{array}{l}123(76.4 \%) \\
\text { (Very high } \\
\text { oxidative stress) }\end{array}$ \\
\hline
\end{tabular}

*TOS: total oxidant status, $\mu$ mol $\mathrm{H}_{2} \mathrm{O}_{2}$ equiv./L; ${ }^{* *}$ TAS: total antioxidant status, mmol Trolox equiv./L, Data presented as $n(\%)$

Table 3: Comparison of patients groups in terms of requirement of early mechanical ventilation

\begin{tabular}{|c|c|c|c|}
\hline Parameters & $\begin{array}{l}\text { Non-MV group } \\
(n=118)\end{array}$ & $\begin{array}{l}\text { MV group } \\
(n=43)\end{array}$ & $p$-value \\
\hline Age, years & $67.21 \pm 16.31$ & $64.40 \pm 19.08$ & 0.356 \\
\hline \multicolumn{4}{|l|}{ Gender, $n(\%)$} \\
\hline Male & $57(48.3)$ & $25(58.1)$ & 0.269 \\
\hline Female & $61(51.7)$ & $18(41.9)$ & \\
\hline \multicolumn{4}{|l|}{ Comorbidity, n (\%) } \\
\hline Hypertension & $41(34.7)$ & $8(18.6)$ & 0.049 \\
\hline Diabetes mellitus & $28(23.7)$ & $8(18.6)$ & 0.490 \\
\hline Renal failure & $29(24.6)$ & $4(9.3)$ & 0.034 \\
\hline Coronary artery disease & $22(18.6)$ & $7(16.3)$ & 0.730 \\
\hline Cerebrovascular disease & $20(16.9)$ & $7(16.3)$ & 0.920 \\
\hline Respiratory diseases & $8(6.8)$ & $13(30.2)$ & $<0.001$ \\
\hline Malignancy & $15(12.7)$ & $4(9.3)$ & 0.553 \\
\hline Heart failure & $12(10.2)$ & $6(14.0)$ & 0.500 \\
\hline Others & $26(22.0)$ & $10(23.3)$ & 0.869 \\
\hline APACHE II score & $22.19 \pm 6.65$ & $28.91 \pm 10.64$ & $<0.001$ \\
\hline SOFA score & $5(3-7)$ & $9(6-13)$ & $<0.001$ \\
\hline $\begin{array}{l}\text { The length of stay in ICU, } \\
\text { days }\end{array}$ & $4(2-7)$ & $8(3-14)$ & 0.002 \\
\hline $\begin{array}{l}\text { The length of stay in } \\
\text { hospital, days }\end{array}$ & $8(5-14)$ & $9(4-17)$ & 0.616 \\
\hline $\begin{array}{l}\text { In-hospital mortality, } n \\
\text { (\%) }\end{array}$ & $27(22.9)$ & $28(65.1)$ & $<0.001$ \\
\hline IL-6, pg/mL* & $\begin{array}{l}14.12 \\
(2.96-36.96)\end{array}$ & $\begin{array}{l}45.04(15.63- \\
671.94)\end{array}$ & $<0.001$ \\
\hline $\mathrm{IAP}, \mu \mathrm{g} / \mathrm{mL}^{*}$ & $\begin{array}{l}320.40 \\
(250.88- \\
341.13)\end{array}$ & $\begin{array}{l}307.50 \\
(248.10- \\
338.20)\end{array}$ & 0.464 \\
\hline $\begin{array}{l}\text { TAS, mmol Trolox } \\
\text { equiv./L* }\end{array}$ & $\begin{array}{l}1.18 \\
(0.95-1.35)\end{array}$ & $\begin{array}{l}1.23 \\
(1.05-1.44)\end{array}$ & 0.172 \\
\hline $\mathrm{TOS}, \mu \mathrm{mol} \mathrm{H}_{2} \mathrm{O}_{2}$ equiv./L* & $\begin{array}{l}19.86 \\
(13.76-33.27)\end{array}$ & $\begin{array}{l}30.26(18.87- \\
53.46)\end{array}$ & 0.003 \\
\hline OSI* & $\begin{array}{l}1.82 \\
(1.15-3.04)\end{array}$ & $\begin{array}{l}2.68 \\
(1.36-4.49)\end{array}$ & 0.021 \\
\hline
\end{tabular}

*Data presented as median (25-75\%); IL-6, interleukin-6; IAP, immunosuppressive acidic protein; TAS, total antioxidant status; TOS, total oxidant status; OSI, oxidative stress index; MV, mechanical ventilation

observed between the two groups in terms of TAS levels $(p=0.172)$, but the median TOS and OSI levels of the patients who required early MV were more statistically significant than the patients not required early $\mathrm{MV}(p=0.003$ and $p=0.021$, respectively). A comparison of patients required and not required early $\mathrm{MV}$ is shown in Table 3. 
Table 4: Comparison of survivors and nonsurvivors

\begin{tabular}{|c|c|c|c|}
\hline Parameters & $\begin{array}{l}\text { Survivors } \\
(n=106)\end{array}$ & $\begin{array}{l}\text { Nonsurvivors } \\
(n=55)\end{array}$ & $p$-value \\
\hline Age, years & $65.33 \pm 18.57$ & $68.64 \pm 13.64$ & $<0.001$ \\
\hline \multicolumn{4}{|l|}{ Gender, $n(\%)$} \\
\hline Male & 55 (51.9) & $27(49.1)$ & 0.736 \\
\hline Female & $51(48.1)$ & $28(50.9)$ & \\
\hline \multicolumn{4}{|l|}{ Comorbidity, $n$ (\%) } \\
\hline Hypertension & $36(34.0)$ & $13(23.6)$ & 0.177 \\
\hline Diabetes mellitus & $25(23.6)$ & $11(20.0)$ & 0.605 \\
\hline Renal failure & $23(21.7)$ & $10(18.2)$ & 0.600 \\
\hline Coronary artery disease & $18(17.0)$ & $11(20.0)$ & 0.636 \\
\hline Cerebrovascular disease & $18(17.0)$ & $9(16.4)$ & 0.921 \\
\hline Respiratory diseases & $16(15.1)$ & $5(9.1)$ & 0.283 \\
\hline Malignancy & $13(12.3)$ & $6(10.9)$ & 0.800 \\
\hline Heart failure & $11(10.4)$ & $7(12.7)$ & 0.654 \\
\hline Others & $24(22.6)$ & $12(21.8)$ & 0.905 \\
\hline APACHE II score & $21.20 \pm 6.72$ & $29.35 \pm 8.83$ & $<0.001$ \\
\hline SOFA score & $5(2-6)$ & $9(6-13)$ & $<0.001$ \\
\hline $\begin{array}{l}\text { The length of stay in ICU, } \\
\text { days }\end{array}$ & $3(2-6)$ & $9(3-16)$ & $<0.001$ \\
\hline $\begin{array}{l}\text { The length of stay in } \\
\text { hospital, days }\end{array}$ & $8(5-13)$ & $9(4-17)$ & 0.608 \\
\hline $\mathrm{IL}-6, \mathrm{pg} / \mathrm{mL}^{*}$ & $\begin{array}{l}10.64 \\
(2.72-25.27)\end{array}$ & $\begin{array}{l}95.75 \\
(22.08-637.58)\end{array}$ & $<0.001$ \\
\hline $\mathrm{IAP}, \mu \mathrm{g} / \mathrm{mL}^{*}$ & $\begin{array}{l}321.70 \\
(252.50- \\
341.13)\end{array}$ & $\begin{array}{l}312.60 \\
(242.30- \\
340.30)\end{array}$ & 0.340 \\
\hline $\begin{array}{l}\text { TAS, mmol Trolox } \\
\text { equiv./L* }\end{array}$ & $\begin{array}{l}1.13 \\
(0.95-1.30)\end{array}$ & $\begin{array}{l}1.33 \\
(1.03-1.48)\end{array}$ & 0.001 \\
\hline TOS, $\mu \mathrm{mol} \mathrm{H}_{2} \mathrm{O}_{2}$ equiv./ $\mathrm{L}^{*}$ & $\begin{array}{l}19.86 \\
(13.40-33.36)\end{array}$ & $\begin{array}{l}26.47 \\
(15.89-48.22)\end{array}$ & 0.024 \\
\hline - & $\begin{array}{l}1.94 \\
(1.21-3.27)\end{array}$ & $\begin{array}{l}2.26 \\
(1.23-4.23)\end{array}$ & 0.207 \\
\hline
\end{tabular}

*Data presented as median (25-75\%); IL-6, interleukin-6; IAP, immunosuppressive acidic protein; TAS, total antioxidant status; TOS, total oxidant status; OSI, oxidative stress index; MV, mechanical ventilation

\section{Comparison of the survivors and Nonsurvivors}

The mean age of the nonsurvivors was significantly higher than the survivors $(p<0.001)$. There was no statistically significant difference in terms of comorbidities between nonsurvivors and survivors ( $p>0.05$ for all). The mean APACHE II and SOFA scores of the nonsurvivors were significantly higher than the survivors $(p<0.001$, for both). No statistically significant difference was found between the two groups in terms of length of stay in the hospital ( $p=0.608)$.

The median IL- 6 levels of the nonsurvivors were significantly higher than the survivors $(p<0.001)$, while there was no statistically significant difference noticed between the patient groups in terms of the median IAP levels $(p=0.340)$. The median TAS and TOS levels of the nonsurvivors were more statistically significant than the survivors ( $p=0.001$ and $p=0.024$, respectively). No statistically significant difference was found in OSI levels between the patient groups ( $p=0.207$ ). A comparison of the survivors and nonsurvivors is shown in Table 4.

The AUCs of IL- 6 and TOS levels for predicting in-hospital mortality were $0.819 \pm 0.038(95 \% \mathrm{Cl}, 0.745-0.893)$ and $0.608 \pm 0.048$ (95\% Cl, 0.515-0.702), respectively (Flowchart 1). In predicting in-hospital mortality, IL-6 showed a sensitivity of $73 \%$ and a
Flowchart 1: The ROC curves of interleukin-6 (IL-6) and total oxidant status (TOS) in terms of predicting in-hospital mortality

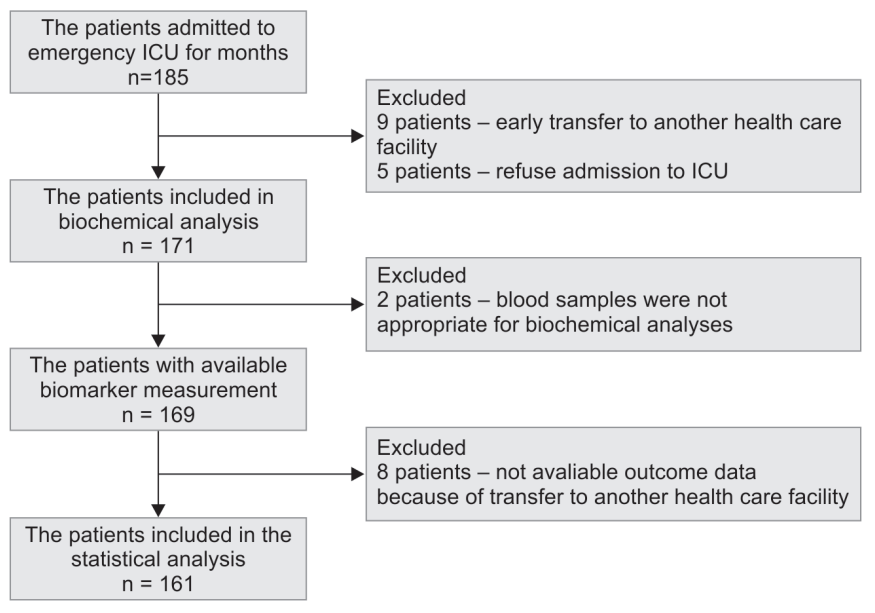

specificity of $77 \%$ with a cutoff value of $26.0 \mathrm{pg} / \mathrm{mL}$, whereas TOS had a sensitivity of $67 \%$ and a specificity of $57 \%$ with a cutoff value of $22.6 \mu \mathrm{mol} \mathrm{H}_{2} \mathrm{O}_{2}$ equiv./L.

\section{Discussion}

In our study, serum IAP levels were measured to evaluate the immunosuppression level. Serum IL-6 levels were measured to evaluate the inflammation level, and serum TOS and TAS levels were measured to evaluate the oxidative stress level in critically ill emergency department patients.

In our study, no statistically significant difference was found between the patient groups in terms of IAP levels for both main outcomes. To the best of our knowledge, this is the first study in the literature that evaluates the level of IAP in non-cancer ICU patients. There is no well-defined range of normal values of IAP levels in the literature. Toiyama et al. used 80 healthy volunteers as the control group and reported the mean IAP levels of the control group as $274.6 \pm 64.4 \mu \mathrm{g} / \mathrm{mL} .{ }^{21}$ Several studies have shown the relationship between serum IAP levels and survival in cancer patients in the literature; however, there is no agreed cutoff point for poor prognosis. It has been reported that cutoff values between 400 and $580 \mu \mathrm{g} / \mathrm{mL}$ are associated with poor prognosis in cancer patients. ${ }^{6,21,22}$ Our findings suggest that serum IAP levels measured on admission to ICU are an ineffective predictor of in-hospital mortality. Our findings also strengthen the idea that the first and only one measured IAP level in general intensive care patients are useless in predicting the need for early MV.

In our study, the blood samples were collected on admission to ICU to measure IAP levels. Our results reflect the IAP levels for the early days of acute physiological stress. In our study, the median IAP levels of patients were measured as $315.3 \mu \mathrm{g} / \mathrm{mL}$ and this value was slightly higher than the mean IAP levels detected in healthy volunteers, but it was significantly lower than the other patients' groups with poor prognosis cutoff values. There are few studies in the literature evaluating the change of IAP levels in time in acute diseases. Ogawa et al., in their study on the effects of surgical stress on cellular immunity, reported that the serum IAP levels decreased below the basal level immediately after the surgery, increased above the basal level after 2 days, and returned to the basal level after 2 weeks. ${ }^{11}$ Shinzeki et al. reported that the IAP reached peak 
levels on the 7th day in patients with mild pancreatitis and the 3rd day in patients with severe pancreatitis. However, the peak IAP levels of patients with severe pancreatitis were lower than the patients with mild pancreatitis. ${ }^{10}$ Our findings support the idea that IAP levels decrease in the early days of acute physiological stress, but could not investigate the changes in IAP levels against time.

In the available literature, there is only one study in which serum IAP levels are investigated in acute inflammatory disease. Shinzeki et al. reported that the serum IAP levels were higher than $500 \mu \mathrm{g} / \mathrm{mL}$ on admission in $88.1 \%$ of patients with acute pancreatitis. However, in the same study, serum IAP levels of the patients who were admitted to the hospital within the first 24 hours after the onset of symptoms were statistically significantly lower than the patients who were admitted within 24-48 hours and 48-72 hours after the onset of symptoms and $4(80 \%)$ of the 5 patients with normal IAP were in the first 24-hour group. ${ }^{10}$ Of the 161 patients in our study, only 19 (12\%) patients had IAP values $>500 \mu \mathrm{g} / \mathrm{mL}$. Our findings contradict the previous finding by Shinzeki et al. that IAP is elevated in the acute inflammatory state. However, we think that this difference occurs since one day is not enough for IAP synthesis and release in the case of acute physiological stress. Shinzeki et al. detected no IAP elevation in $80 \%$ of patients admitted in the first 24 hours. ${ }^{10}$

In our study, serum IL-6 levels were statistically significantly higher in patients who required early MV than in patients not required early MV. The AUC value of IL- 6 in predicting in-hospital mortality of ICU patients was 0.819 and the optimum cutoff value was $26.0 \mathrm{pg} /$ $\mathrm{mL}$. Several studies in the literature showed that IL- 6 is a useful prognostic indicator in ICU patients. ${ }^{24-26}$ In the study conducted on patients undergoing major thoracic surgery by Fink-Neuboeck et al., the peak level of serum IL- 6 levels was reported to be higher in the general patient group one day after the surgical operation and in patients with systemic inflammatory response syndrome. ${ }^{25}$ Similar to Fink-Neuboeck et al., our study findings showed that serum IL-6 levels are elevated in the early stage of acute physiological stress and are directly related to prognosis. Our findings suggest that IL- 6 is a strong prognostic marker in predicting in-hospital mortality and that a lower threshold value of $25 \mathrm{pg} / \mathrm{mL}$ for in-hospital mortality estimation may contribute to patient care in general intensive care units.

In our study, the median IL-6 level measured on ICU admission was 3 times higher than normal, but there was no significant correlation between IAP and IL- 6 levels. Our results show that despite an elevation in serum IL- 6 levels in the early days of acute physiological stress, IAP levels did not increase. The data presenting all possible pathways associated with elevation of serum IAP levels in the blood and reporting the time relationship between secretion of cytokines and IAP synthesis are not available in the literature yet. Our results suggest that there may be a few days difference between the elevation of IL- 6 levels in the blood and IAP synthesis and release to blood during acute physiological stress, but this hypothesis should be investigated with appropriate design studies.

Oxidative stress is defined as the deterioration of the balance between reactive oxygen species and the antioxidant capacity of an organism. ${ }^{20}$ In our study, the median TAS level was found as $1.19 \mathrm{mmol}$ Trolox Equiv./L, and TOS level as $22.92 \mu \mathrm{mol}$ $\mathrm{H} 2 \mathrm{O} 2$ equiv./L in the patient population. Furthermore, general ICU patients showed a very high oxidative burden and low antioxidant status during ICU admission, independently from etiology. In addition, approximately $95 \%$ of our patients were in the high oxidative stress or very high oxidative stress group and general ICU patients were under high oxidative stress.
It has been reported that oxidative stress is a common pathophysiological pathway of many diseases. ${ }^{14-16}$ Dur et al., in a study on patients with acute pancreatitis, reported that TOS levels of acute pancreatitis are higher than healthy volunteers and TAS levels are lower than healthy volunteers. ${ }^{17}$ Atik et al. in their study on patients with acute stroke in the emergency documented that the patients with acute stroke had higher levels of TOS and OSI than normal healthy individuals. ${ }^{27}$

In our study, the mean TOS and OSI values of the patients who required early $M V$ were found more statistically significant than those not required early MV with no statistically significant difference between the two groups in terms of TAS levels. These findings suggest that early period morbidities may be more common in general ICU patients with higher oxidative stress burden.

In our study, the mean TAS and TOS levels of the nonsurvivors were significantly higher than the survivors, but there was no statistically significant difference between the survivors and the nonsurvivors in terms of OSI values. We also observed that TAS levels are not useful in terms of showing in-hospital mortality in ICU patients. Although the balance between TOS and TAS (OSI) is not useful to discriminate the patients with a high risk of in-hospital mortality, the increased TOS levels show that the patients with increased oxidative stress burden have more in-hospital mortality. Our results should be reevaluated with further studies on larger populations.

\section{Conclusion}

Our results show that the level of IAP measured on admission to ICU in critically ill patients is ineffective in predicting the need for early MV and in-hospital mortality. Furthermore, IL- 6 is a strong prognostic indicator in predicting in-hospital mortality, and the lower threshold values such as $25 \mathrm{pg} / \mathrm{mL}$ for in-hospital mortality estimation may contribute to patient care in general ICUs. Our findings show that the burden of oxidative stress is high in general ICU patients.

\section{Clinical Significances}

Our study shows that increased oxidative stress is the major problem in critically ill patients. If proper and timely measures are taken to reduce oxidative stress by physicians, the prognosis of critically ill patients will be better.

\section{SOURCE OF SUPPORT}

The study was supported by the Research Fund of Necmettin Erbakan University (Project no. 151518006).

\section{ORCID}

Elif O Tutuncu: @https://orcid.org/0000-0003-2483-0490, Zerrin D Dundar: (1) https://orcid.org/0000-0001-6431-5800,

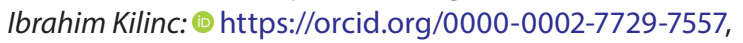
Aziz Tutuncu: @ https://orcid.org/0000-0003-0282-8947, Sedat Kocak: @ https://orcid.org/ 0000-0001-8265-9615, Abdullah S Girisgin: @ https://orcid.org/ 0000-0003-2669-0532

\section{References}

1. Berger MM, Soguel L, Shenkin A, Revelly JP, Pinget C, Baines M, et al. Influence of early antioxidant supplements on clinical evolution and organ function in critically ill cardiac surgery, major trauma, and subarachnoid hemorrhage patients. Crit Care 2008;12:R101. DOI: 10.1186/cc6981. 
2. Motoyama T, Okamoto K, Kukita I, Hamaguchi M, Kinoshita Y, Ogawa H. Possible role of increased oxidant stress in multiple organ failure after systemic inflammatory response syndrome. Crit Care Med 2003;31(4):1048-1052. DOI: 10.1097/01.CCM.0000055371. 27268.36.

3. Hawkins RB, Raymond SL, Stortz JA, Horiguchi H, Brakenridge SC, Gardner A, et al. Chronic critical illness and the persistent inflammation, immunosuppression, and catabolism syndrome. Front Immunol 2018;9:1511. DOI: 10.3389/fimmu.2018.01511.

4. Tamura K, Shibata Y, Matsuda Y, Ishida N. Isolation and characterization of a immunosuppressive acidic protein from ascitic fluids of cancer patients. Cancer Res 1981;41:3244-3252.

5. Sadahiro S, Suzuki T, Maeda Y, Tanaka A, Kamijo A, Murayama C, et al. Effects of preoperative immunochemoradiotherapy and chemoradiotherapy on immune responses in patients with rectal adenocarcinoma. Anticancer Res 2010;30(3):993-999.

6. Ebina T, Fujimiya Y. Cell transfer regimens in patients with highly advanced surgically unresectable non-small cell lung cancer: significantly improved overall survival in patients with lower levels of serum immunosuppressive acidic protein. Lung Cancer 2008;60(2):246-251. DOI: 10.1016/j.lungcan.2007.09.016.

7. Araki K, Igarashi T, Tobe T, Mizoguchi K, Suzuki H, Furuya Y, et al. Serum immunosuppressive acidic protein doubling time as a prognostic factor for recurrent renal cell carcinoma after nephrectomy. Urology 2006;68(6):1178-1182. DOI: 10.1016/j.urology.2006.08.1071.

8. Ikuta S, Miki C, Tanaka K, Konishi N, Mohri Y, Tonouchi H, et al. Serum immunosuppressive acidic protein as an interleukin- 6 related index of deteriorating condition in gastric cancer patients. Dig Surg 2003;20(6):532-538. DOI: 10.1159/000073700.

9. Ueyoshi A, Ota K. Evaluation of immunosuppressive acid protein (IAP) in patients with rheumatoid arthritis. Ryumachi 1992;32(2): 131-134.

10. Shinzeki M, Ueda T, Takeyama Y, Yasuda T, Sawa H, Nakajima T, et al. Serum immunosuppressive acidic protein levels in patients with severe acute pancreatitis. Pancreas 2007;35(4):327-333. DOI: 10.1097/ mpa.0b013e3181200222.

11. Ogawa K, Hirai M, Katsube T, Murayama M, Hamaguchi K, Shimakawa $\mathrm{T}$, et al. Suppression of cellular immunity by surgical stress. Surgery 2000;127(3):329-336. DOI: 10.1067/msy.2000.103498.

12. Yamashita $Y$, Shimada M, Hamatsu T, Rikimaru T, Tanaka S, Shirabe $\mathrm{K}$, et al. Effects of preoperative steroid administration on surgical stress in hepatic resection: prospective randomized trial. Arch Surg 2001;136(3):328-333. DOI: 10.1001/archsurg.136.3.328.

13. Rabus M, Demirbağ R, Sezen Y, Konukoğlu O, Yildiz A, Erel O, et al. Plasma and tissue oxidative stress index in patients with rheumatic and degenerative heart valve disease. Turk Kardiyol Dern Ars 2008;36(8):536-540.

14. Morelli NR, Scavuzzi BM, Miglioranza LHDS, Lozovoy MAB, Simão ANC, Dichi I. Metabolic syndrome components are associated with oxidative stress in overweight and obese patients. Arch Endocrinol Metab 2018;62(3):309-318. DOI: 10.20945/2359-3997000000036.
15. Schrutka L, Goliasch G, Meyer B, Wurm R, Koller L, Kriechbaumer L, et al. Impaired high-density lipoprotein anti-oxidant function predicts poor outcome in critically ill patients. PLoS One 2016;11:e0151706. DOI: 10.1371/journal.pone.0151706.

16. Ranjbar A, Solhi H, Mashayekhi FJ, Susanabdi A, Rezaie A, Abdollahi M. Oxidative stress in acute human poisoning with organophosphorus insecticides; a case control study. Environ Toxicol Pharmacol 2005;20(1):88-91. DOI: 10.1016/j.etap.2004.10.007.

17. Dur A, Kocaman O, Koçyiğit A, Türkdoğan KA, Sönmez E, Keskin S, et al. Oxidative status and lymphocyte DNA damage inpatients with acute pancreatitis and its relationship with severity of acute pancreatitis. Turk J Gastroenterol 2016;27(1):68-72. DOI: 10.5152/tjg.2015.150317.

18. Erel O. A novel automated method to measure total antioxidant response against potent free radical reactions. Clin Biochem 2004;37(2):112-119. DOI: 10.1016/j.clinbiochem.2003.10.014.

19. Erel O. A new automated colorimetric method for measuring total oxidant status. Clin Biochem 2005;38(12):1103-1111. DOI: 10.1016/j. clinbiochem.2005.08.008.

20. RelAssay. Oxidatıve Stress Measurement and Evaluation https://www. relassay.com/uploads/OxidativeGuideline.pdf [accessed 18 January 2019].

21. Toiyama $Y$, Miki C, Inoue $Y$, Okugawa $Y$, Koike $Y$, Watanabe $H$, et al. Serum immunosuppressive acidic protein reflects systemic deterioration of colorectal cancer patient condition. J Surg Oncol 2008;97(5):404-408. DOI: 10.1002/jso.20966.

22. Kogure M, Kashimura S, Matsuyama S, Ohtani S, Saze Z, Odashima Y, et al. Prognostic role of immunosuppressive acidic protein in patients with esophageal cancer. Dis Esophagus 2008;21(3):214-219. DOI: 10.1111/j.1442-2050.2007.00754.x.

23. Takahashi W, Nakada TA, Yazaki M, Oda S. Interleukin- 6 levels act as a diagnostic marker for infection and a prognostic marker in patients with organ dysfunction in intensive care units. Shock 2016;46(3):254260. DOI: $10.1097 /$ SHK.0000000000000616.

24. Dieplinger B, Egger M, Leitner I, Firlinger F, Poelz W, Lenz K, et al. Interleukin 6 , galectin 3 , growth differentiation factor 15 , and soluble ST 2 for mortality prediction in critically ill patients. J Crit Care 2016;34:38-45. DOI: 10.1016/j.jcrc.2016.03.020.

25. Fink-Neuboeck N, Lindenmann J, Bajric S, Maier A, Riedl R, Weinberg $A M$, et al. Clinical impact of interleukin 6 as a predictive biomarker in the early diagnosis of postoperative systemic inflammatory response after major thoracic surgery: A prospective clinical trial 2016;160(2):443-453. DOI: 10.1016/j.surg.2016.04.004.

26. Mat-Nor MB, Md Ralib A, Abdulah NZ, Pickering JW. The diagnostic ability of procalcitonin and interleukin- 6 to differentiate infectious from noninfectious systemic inflammatory response syndrome and to predict mortality. J Crit Care 2016;33:245-251. DOI: 10.1016/j. jcrc.2016.01.002.

27. Atik I, Kozacı N, Beydilli İ, Avcı M, Ellidağ H, Keşaplı M. Investigation of oxidant and antioxidant levels in patients with acute stroke in the emergency service. Am J Emerg Med 2016;34(12):2379-2383. DOI: 10.1016/j.ajem.2016.08.062. 